\title{
Entrevista Patrícia Bellodi - Tutoria
}

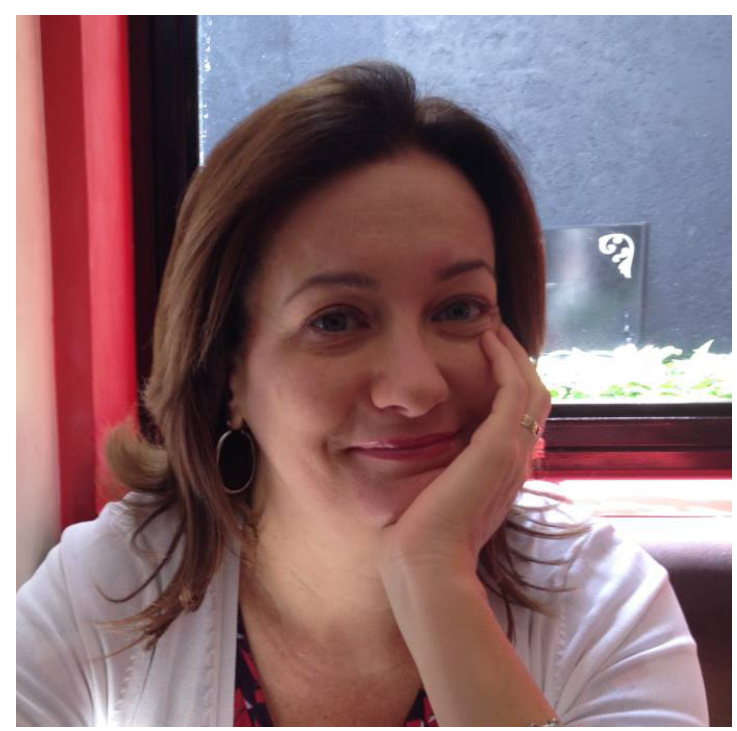

\section{Patrícia Lacerda Bellodi}

Psicóloga pela Universidade de São Paulo (1989), com Mestrado e Doutorado em Psicologia Clínica pela mesma universidade (1994 e 1999). É coordenadora do Programa de Tutoria/Mentoring da Faculdade de Medicina da Universidade de São Paulo (FMUSP), desde 2000, e Orientadora (Mestrado) no Curso de Pós Graduação do Depto. de Medicina Preventiva. Tem experiência na área de Psicologia Médica e Educação Médica e Avaliação de Personalidade. Autora dos livros O Clínico e o Cirurgião (2001) e Tutoria Mentoring na Formação Médica (2005), Editora Casa do Psicólogo.

\section{Como a tutoria começou? Com qual intenção?}

A Tutoria começou em 2001 com o propósito de orientar os alunos nas escolhas e decisões relativas ao presente acadêmico e ao futuro profissional. Ela surge no contexto de uma série de mudanças curriculares no curso de graduação na década de 90 (novas disciplinas, possibilidade de construção de um currículo personalizado, por meio das optativas), onde se considerou importante o diálogo e o contato com figuras experientes - os tutores (com papel de mentores), que pudessem acompanhar os alunos no caminho da construção do ser médico - os tutores (mentores).

\section{Qual a importância da tutoria para os alunos?}

$\mathrm{Na}$ Tutoria, os alunos contam com a proximidade e a orientação de um médico experiente (o tutor/mentor) que já trilharam o caminho do vir-a-ser médico. Os tutores compartilham com os alunos sua história, as vicissitudes e as recompensas do ser médico e, nessa troca, os alunos podem se projetar no futuro, fazer escolhas mais bem orientados, antecipar e se preparar para momentos difíceis, assim para as alegrias da futura profissão. Na tutoria há possibilidade de se experimentar suporte (do tutor e dos colegas de grupo), desenvolvimento e ampliação de visão (do curso, da Medicina, da profissão).

3. Por que a tutoria agora conta pontos na residência? (Sugestões sobre outras formas de aumentar a aderência ao programa).

A Tutoria passou a fazer parte dos editais de Residência porque, tal como tantas outras atividades realizadas pelos alunos, também contribui de forma importante para o desenvolvimento pessoal e profissional do futuro médico. Ela ganhou o mesmo reconhecimento que outras atividades como ligas, iniciação científica, participação em instituições acadêmicas, etc.

\section{Há algum estudo científico sobre a tutoria da FMUSP? E de outras instituições?}

Sim, além do livro "Tutoria - Mentoring na Formação Médica” (2005), nós já publicamos vários artigos sobre a Tutoria FMUSP. Eles são derivados tanto de pesquisas qualitativas quanto quantitativas, fruto de mestrados, iniciação científica e investigações da própria coordenação sobre a qualidade e o impacto do programa. A pesquisa em Mentoring é vasta, com relatos de experiências de outras instituições, dentro e fora do Brasil. Nossa produção científica:

\section{a) Artigos}

$\checkmark$ Gonçalves, Marina de Castro Nascimento; Bellodi, Patricia Lacerda. Mentors also need support: a study on their difficulties and resources in medical schools. São Paulo Medical Journal (Impresso), v. 130, p. 252-8, 2012.

$\checkmark$ Gonçalves, Marina de Castro Nascimento; Bellodi, Patrícia Lacerda. Ser mentor em medicina: uma visão arquetípica das motivações e transformações na jornada. Interface (Botucatu. Impresso), v. 16, p. 501-14, 2012. 
Bellodi, Patrícia Lacerda; Chebabo, Rachel; Abensur, Sílvia Itzcovici; Martins, Milton de Arruda. Mentoring, ir ou não ir, eis a questão - um estudo qualitativo. Revista Brasileira de Educação Médica (Impresso), v. 35, p. 237-45, 2011.

$\checkmark$ Bellodi, Patrícia Lacerda. Mentors, students, and the undergraduate course - a virtuous circle. Revista Brasileira de Educação Médica (Impresso), v. 35, p. 382-8, 2011.

$\checkmark$ Abensur, Silvia I.; Bellodi, Patricia Lacerda; Chebabo, Rachel; Martins, Milton A. Programa Tutores na Internet: Sistema de gerenciamento. Revista Digital de Educação Permanente em Saúde, v. 29, p. 534, 2005.

$\checkmark$ Bellodi, Patrícia Lacerda. Temas para um programa de tutoria em medicina: uma investigação das necessidades dos alunos da FMUSP. Revista Brasileira de Educação Médica, v. 28, n.2, p. 89184, 2004.

$\checkmark$ Bellodi, Patrícia Lacerda. O Programa Tutores e a integração dos calouros na FMUSP. Revista Brasileira de Educação Médica, v. 28, n.3, p. 20414, 2004.

$\checkmark$ Bellodi, Patrícia Lacerda. O que é um tutor? Representações do papel em um grupo de professores de medicina durante o processo de seleção. Revista Brasileira de Educação Médica, v. 27, n.3, p. 20512, 2003.

$\checkmark$ Bellodi, Patrícia Lacerda; Martins, Milton de Arruda. Projeto Tutores: Da proposta à implantação na graduação da Faculdade de Medicina da Universidade de São Paulo/FMUSP. Revista de Medicina do Hospital Universitário (USP) (Cessou em 2000. Cont. ISSN 1519-6623 Revista do Hospital Universitário (USP), São Paulo, v. 11, n.1/2, p. 52-8, 2001.

\section{b) Livros e Capítulos de livros publicados}

$\checkmark$ Bellodi, Patrícia Lacerda; Martins, Milton de Arruda. Tutoria - mentoring na formação médica. São Paulo: Casa do Psicólogo, 2005. v. 1, 370p.

Bellodi, Patrícia Lacerda. Como tutores cuidam do estudante de Medicina: intervenções terapêuticas em Mentoring. In: Baldassin, Sergio, organizador. Atendimento psicológico aos estudantes de medicina - técnica e ética. São Paulo: Edipro, 2012. v. 1, p. 151-60.

\section{Como a tutoria da faculdade é diferente das demais?}

A Tutoria FMUSP é diferente das demais especialmente por conta da formação dos grupos com alunos de todos os anos acadêmicos. Ela também se destaca por ocorrer num dia/horário específico, dentro da grade horária do aluno, com dispensa oficial das demais atividades.

\section{Quais foram os resultados obtidos desde a implantação do programa?}

Parte importante dos alunos (60\%), em suas avaliações anuais (por meio de um questionário denominado "O Tutorando") revela que conhecem melhor o curso, ampliaram suas amizades e, especialmente, veem a Medicina de forma mais positiva. A Tutoria é também uma via de mão dupla: os tutores, em suas avaliações, relatam transformações importantes: como professores, como membros da faculdade e como pessoa.

\section{Qual o feedback dos alunos? E dos professores?}

Resposta acima!

\section{Quais são os projetos futuros?}

A Tutoria pretende apostar mais em eventos que divulguem seus propósitos entre os próprios alunos e demais professores e médicos da instituição, como a Cerimônia do Avental (na recepção de calouros, já em sua segunda edição). Pretende também, a partir das necessidades e interesses dos alunos, realizar eventos que os auxiliem em escolhas presentes e futuras: agora, em outubro de 2013, realizou-se o I Road Show FMUSP de Especialidades Médicas. E, por fim, mas não menos importante, queremos ampliar o conceito de mentoring para além das reuniões mensais, isto é, desejamos compartilhar com todos os alunos as experiências interessantes vividas pelos diferentes tutores. Isso já está acontecendo via a publicação, no Bisturi, da seção "Meninos, eu vi!", e aqui na Revista de Medicina, na seção "12 Dicas de Tutoria". 